\title{
13 \\ RHYTHMIC FUNCTIONS \\ IN POP-ROCK MUSIC
}

\author{
Nicole Biamonte
}

One of the most striking aspects of popular music is its rhythm, because of the explicit beat layer typically provided by the drums, the use of rhythmic dissonance in multiple layers of the musical texture, high degree of repetition, and brief length of repeated units. Numerous studies on rhythm in popular music have explored the ways in which the layers of a groove - a short repeating accompaniment pattern - interlock, ${ }^{1}$ but fewer have considered the trajectories of individual layers. Olly Wilson andVijay Iyer have described AfricanAmerican popular musics as rhythmically stratified, but provide only a few brief examples. ${ }^{2}$ The same idea underpins some analyses by Jonathan Pieslak in Meshuggah and John Brackett in Led Zeppelin, and a theoretical model has been developed by John Covach. ${ }^{3}$ Robin Attas has considered the polyphonic aspects of disco and Motown grooves, but her adoption of Christopher Hasty's projective model of rhythm renders the analyses information-dense and somewhat difficult to generalize. ${ }^{4}$ Much more frequently, the concept of rhythmic stratification has been applied to the music of twentieth-century composers of art music such as Ives, Schoenberg, Bartók, Stravinsky, Cowell, Carter, and Nancarrow, ${ }^{5}$ and to a lesser extent, tonal art music. ${ }^{6}$

Most studies of syncopated rhythms in popular music focus on ways in which the melodic layer is dissonant against an abstract metrical grid. ${ }^{7}$ A horizontal rather than vertical approach to texture, in contrast, reflects its inherent timbral and registral differentiation, which allows listeners to perceive different instruments as separate auditory streams. ${ }^{8}$ More importantly for purposes of this study, a horizontal approach reflects the comparatively loose rhythmic coordination among the layers of the texture: the "melodic-harmonic divorce" 9 characteristic of rock music, in which the melody has some degree of independence from the harmony, is often a rhythmic one. Listener perception of individual rhythmic streams in popular music is aided by the common formal technique of the "buildup introduction", in which the texture gradually accumulates as layers enter separately at the beginning of a song, ${ }^{10}$ and also by the performance technique of microtiming variations among the parts. ${ }^{11}$

The first part of this chapter surveys existing models of texture in popular music, identifies the rhythmic characteristics of the different layers, and offers sample analyses drawn from Anglophone popular music from the mid- to late twentieth century that demonstrate various rhythmic functions. The second part describes typical textural and rhythmic 
characteristics of formal sections, again illustrated with sample analyses. My analyses adapt a theory developed for Classical music to a vernacular repertoire: William Caplin's theory of formal functions, in which particular formal roles (the basic functions of beginning, middle, and end, and the framing functions of before-the-beginning and after-the-end) and behaviours (such as tight- or loose-knit, stable or unstable) are associated with formal units at both large and small structural levels. ${ }^{12}$ Within phrases and formal sections, the rhythmic layers of the texture can help to create stability, momentum, tension, or ambiguity. Between song sections, rhythmic and metric shifts mark the formal boundaries of phrases, sections, and section groupings (such as verse-prechorus-chorus), and help to articulate larger trajectories of increasing and decreasing intensity throughout the song.

Covach has posited several types of textural stratification that fill the continuum from complete coordination to complete independence. ${ }^{13}$ "Coordinated structure" consists of the tight synchronization of all layers; "momentary stratification" comprises a brief uncoordinated passage. "Pedal point" features a static layer separate from the rest of the texture, "ostinato" comprises a less static layer with a repeating motive distinct from the rest of the texture, and in "melodic-harmonic divorce" the melody diverges from a coordinated accompaniment. Note that each of these three types has two textural layers; the difference among them is the level of differentiation within the accompaniment layer. In "textural stratification" there are three or more separate layers with periodic points of alignment, and in "full stratification" — as in some avant-garde music or free jazz-there are no recurring points of coordination after the initial one.

Several other scholars have observed that various rhythmically complex vernacular musics - including West African musics, rock, gospel, jazz, disco, and rap-often consist of a variable rhythmic layer and a fixed rhythmic layer in a figure-ground relationship. ${ }^{14}$ This two-layer model of texture closely resembles Covach's categories of "ostinato" and "melodic-harmonic divorce". Jeff Pressing makes the same figure-ground analogy between variable speech-like rhythms and the repeating cycle of groove in "Black Atlantic" rhythm, and this duality is also implicit in the idea of the melodic-harmonic divorce. ${ }^{15}$ Recent work by Trevor de Clercq expands this model to three layers in a discussion of the "harmonicbass divorce". ${ }^{16}$

Allan Moore describes the basic model of texture in rock music as comprising four layers that are registrally and often timbrally distinct. ${ }^{17}$ The "explicit beat layer" maintains a basic pulse and usually a regular meter; it is largely unpitched and played on drums or other percussion, and its presence is an important marker distinguishing art music from popular music. The "melodic layer" is normally in the topmost register, most often articulated by vocals or lead guitar, with a distinctive melodic and rhythmic contour that makes it the most memorable and salient layer of the song. The "functional bass layer" occupies the lowest register, played on electric bass or sometimes synthesiser, and is typically structured more closely around chord roots than the bass layer in art music. The "harmonic filler layer" is situated in the middle register, filling the registral space between the melodic and bass layers, and commonly played by rhythm guitar and/or keyboard. The explicit beat layer reflects rock's origins in dance music; in addition to its basic timekeeping function, it affords an intensified entrainment to the metre that facilitates kinesthetic engagement, and also allows for greater rhythmic complexity in other layers. ${ }^{18}$ The rhythmic consistency of these four layers ranges from repeated, unchanging rhythmic patterns that function as timelines to variable, improvisatory ones. The explicit beat layer is the most firmly fixed, followed by the harmonic filler layer. The functional 
bass layer is more likely to be variable, and the melodic layer is the most variable, in part (but not entirely) because of the need to adapt the music to different numbers of syllables in the changing lyrics. The melody layer is inherently variable because its differentiated rhythms help to make it the most salient and memorable layer.

The explicit beat layer in rock and related genres beginning in the early 1950s is typically some version of a crotchet backbeat in 4/4 played on a drum kit, with kick drum on beats 1 and 3, snare on beats 2 and 4, and hi-hat or ride cymbal iterating even quaver subdivisions (Figure 13.1a). Uneven quavers in a swung or shuffle rhythm are common in popular musics from the first half of the twentieth century, but far less so after that. ${ }^{19}$ The snare drum is higher in pitch, has a sharper timbre, and is usually louder than the kick drumthus it is registrally, timbrally, and dynamically more prominent, placing several types of phenomenal accent on what are traditionally the weak beats in 4/4. I have suggested elsewhere that the repeated registral traversals of the backbeat suggest or impel motion, ${ }^{20}$ and Iyer interprets the backbeat as a modern iteration of foot stomps and hand claps in a ring shout; ${ }^{21}$ Queen famously returned to this early version of the pattern in "We Will Rock You." Iyer further asserts that the backbeat is inherently polyphonic because of microtiming variations between the kick and snare drums. ${ }^{22}$ Thus the kick-snare pattern is mildly stratified, but it does not comprise a rhythmic dissonance: it is a foundational unit that does not need to resolve. ${ }^{23}$ The backbeat pattern also creates a clear distinction between oddnumbered and even-numbered beats of the metre, thus articulating three different levels of temporal organisation: the bar (or, more precisely, the repeated half-bar), the beat, and the beat subdivision.

The most normative beats in pop-rock are the basic backbeat and close variants of it. ${ }^{24}$ There are many possible versions - those in funk are quite complex-but the most common alternatives add or delay hits to the quaver off-beats (as in Figures 13.1b and 13.1c) or omit them (as in Figure 13.1d). These and the many other possible variant backbeat patterns confirm that the basic metric unit in rock drumming is the bar, rather than the half-bar defined by the kick-snare grouping. ${ }^{25}$ Another widespread pattern, most prevalent in disco and electronic dance music but also used in rock and metal, is four-on-the-floor (not shown), which has a kick-drum hit on every beat. ${ }^{26}$ In practice, these drum beats usually remain fairly consistent within formal sections of a song, but often incorporate fills of greater rhythmic density at the end of a phrase or section that mark the formal boundary and act as anacruses to the next unit, analogous to the acceleration in surface rhythm and harmonic rhythm often leading into cadences in art music. The difference in pop-rock music is that phrases and song sections often do not end with cadences, so the goal of the increased momentum is not the end of the formal unit, but the beginning of the next one.

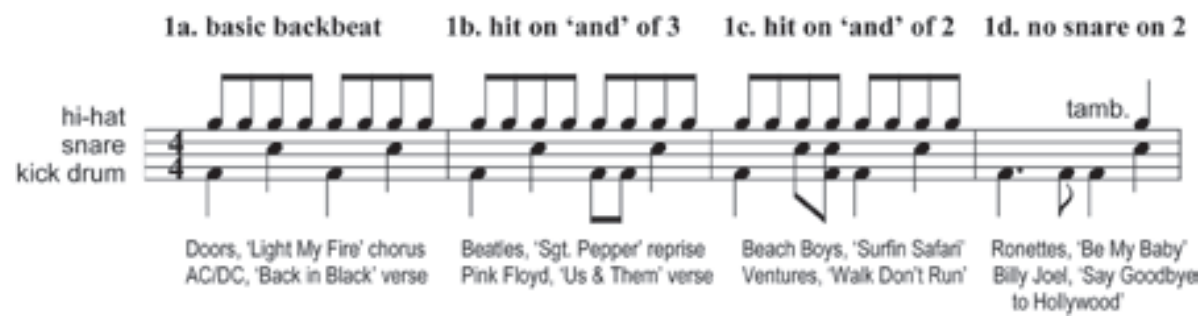

Figure 13.1 Sample backbeat patterns 
The harmonic filler layer often has a dual function as a rhythmic filler layer. The most common patterns in accompanimental guitar and keyboard parts have chords or arpeggiations in even rhythms or mild syncopations displaced by a quaver. Most often rhythmic patterns repeat in 1- or 2-bar units, either consistently or in a call-and-response with the vocals. Static, sustained chords are also fairly common. The functional bass layer is realized in a greater variety of guises: distinctive rhythmic and melodic contours that may be variable (as in Paul McCartney's melodic bass lines) or fixed as a short repeated riff, "walking" patterns in even notes, arpeggiations of the harmony, or repeated or sustained chord roots.

As noted, the melodic layer is the most rhythmically variable, and the most likely to be dissonant against the other parts. Although there are many possible rhythmic interactions of the melodic layer with the explicit beat layer, it is fairly common for the melody to provide a rhythmic counterpoint to the backbeat by emphasising beats other than 2 and 4: either the "front beats" 1 and 3, or the quaver off-beats. In the chorus of the Rolling Stones' "It's Only Rock and Roll" (1974), beats 1 and 3 are emphasised by the contour and text stress of the vocal line and most of the attacks in the lead guitar. The last phrase of the first chorus is shown in Figure 13.2. In this and the following examples, the points of emphasis are marked by arrows above the staff for vocals, guitars, and keyboards, and below the staff for bass and drums. The arrows are based on rhythmic grouping, duration, contour, and text stress in the vocal line: I interpret beginnings of groupings, comparatively long notes, contour high and low points, and accented syllables in the lyrics as being emphasized.

This is mostly a coordinated texture, with a momentary melodic-harmonic divorce at the end of the third bar, when the vocals repeat the falling third G to E over D major harmony. In the first and last bars, the third beat is anticipated by a quaver, but the basic structure of the line emphasises beats 1 and 3. The extra hits in the kick drum are on the "and" of beats 1 or 3 , and they correlate with notes in the bass layer, which is very common. The snare hits in the drums, in contrast, emphasise the backbeat, as does the upperneighbour contour of the rhythm guitar in the first two bars, though to a lesser degree. The rhythm guitar and drums comprise a mostly fixed rhythmic layer that accompanies the variable rhythmic layers of the vocals and lead guitar. In the fourth bar, the snare hit that would normally be on beat 2 is delayed by a quaver, so that the vocals, rhythm guitar, bass,

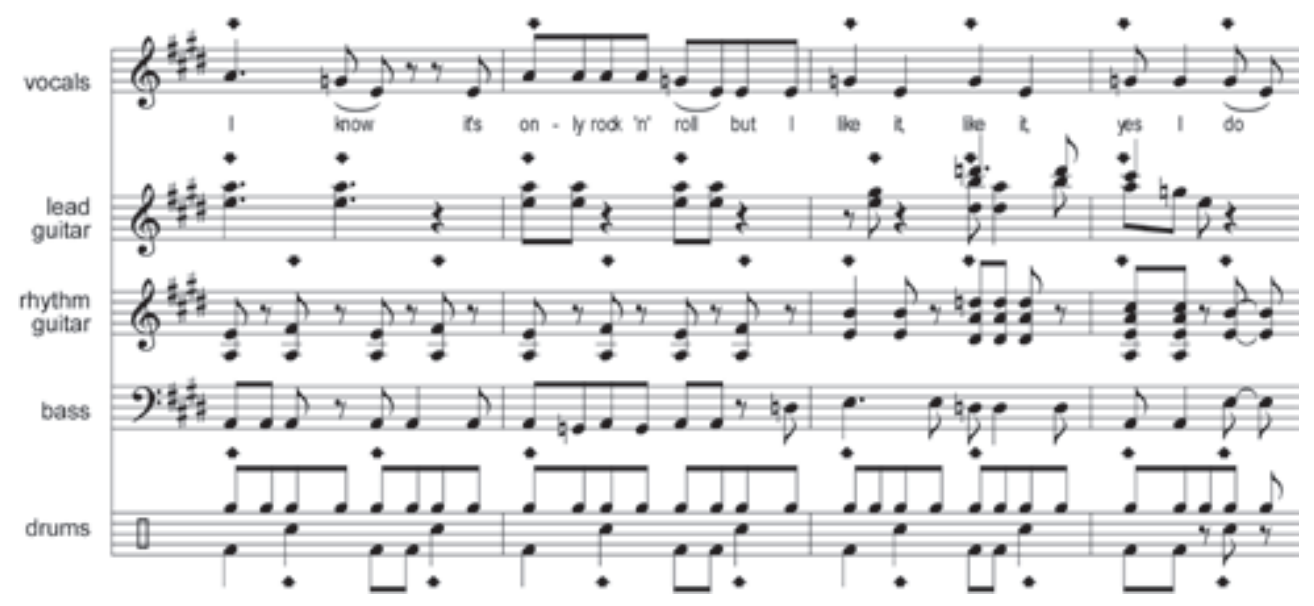

Figure 13.2 Rolling Stones, "It's Only Rock and Roll”, last phrase of chorus 1 (not shown: acoustic guitars and guitar overdubs, piano, or backbeat handclaps) 
and snare all align, creating an accent that signals the end of the phrase and underscores the affirmation "yes I do" in the lyrics. The early arrival of the last two syllables is a very common rhythmic pattern in rock that I call a "cadential displacement", a rhythmic intensification at the end of a phrase analogous to a cadential hemiola. The sentential structure of this phrase also contributes to the sense of a strong arrival in bar 4: a one-bar basic idea in the melody is followed by a variation with increased rhythmic density in the second bar, then fragmentation and a faster harmonic rhythm in the third bar, culminating with a double-plagal cadence in the last bar of the Figure 13.2. Other examples of melodies that emphasise beats 1 and 3, complementing the backbeat, are The Doors' "Light My Fire" and the choruses of The Who's "Substitute" and Free's "All Right Now."

A vocal melody that complements the backbeat through emphasis on the quaver offbeats is the verse of Led Zeppelin's "Houses of the Holy" (1973). The opening of the first verse is shown in Figure 13.3. This is an even more coordinated texture, both harmonically and rhythmically: the guitar and bass follow the melodic rhythm, creating a series of accents on the off-beats that do not align with the snare backbeats. As in the previous example, all of the extra kick-drum hits align with a bass note, reinforcing the low register. The melody is displaced throughout the first four verses, but in the last two verses many more of the attacks are on the beat. These closing verses are sung in a much higher register with denser rhythmic activity, while backing vocals add an "ooh" on each beat. Thus the decrease in rhythmic dissonance in the melody, rather than acting as a large-scale rhythmic resolution, compensates for the increased intensity in other parameters. Other songs featuring melodies that are fairly consistently displaced by a quaver are the verse of Bob Dylan's "Knockin' on Heaven's Door", the chorus of the Doobie Brothers' "South City Midnight Lady", and The Beatles' "Here Comes the Sun". ${ }^{27}$

More commonly, off-beat melodies realign with the metre every two or four bars. Most of the attacks in the melody of the Rolling Stones' "Satisfaction" (1965) occur off the beat (see Figure 13.4). The rhythm of the melodic layer can be analysed as a series of displacements by crotchets and quavers, or as a grouping of 233332 (a "rotated double tresillo"28). In contrast to the syncopated melodic layer, the bass emphasises beats 1 and 3 , and the drum plays a four-on-the-floor pattern. The lead guitar mediates between figure and ground,

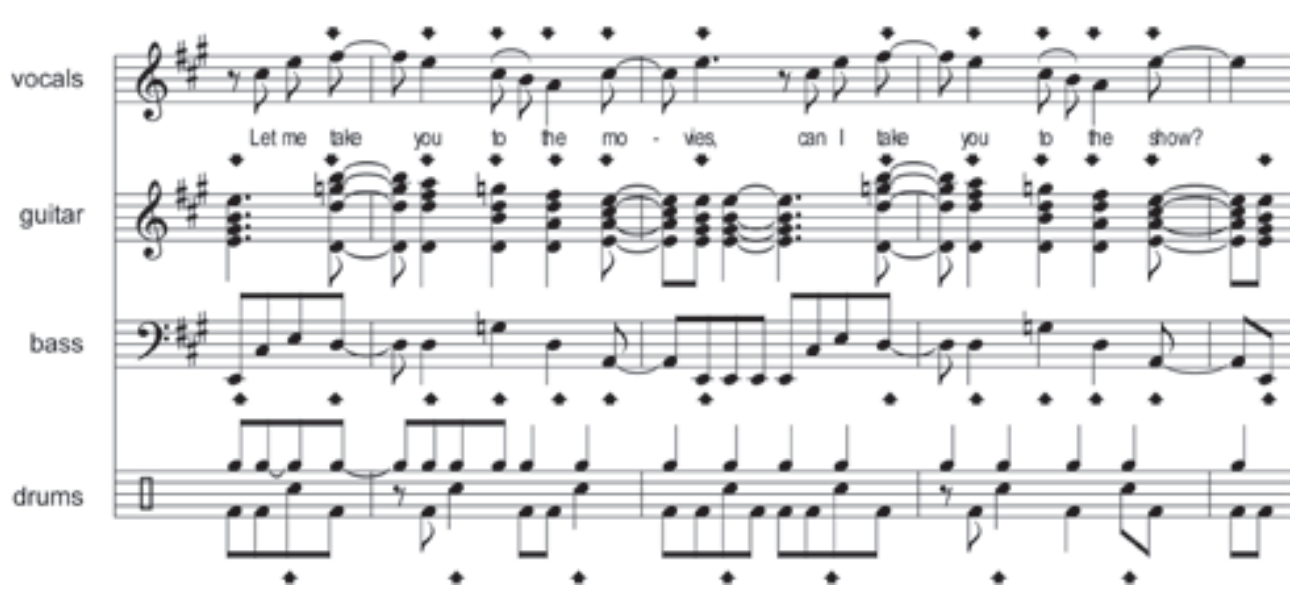

Figure 13.3 Led Zeppelin, "Houses of the Holy", first half of verse 1 


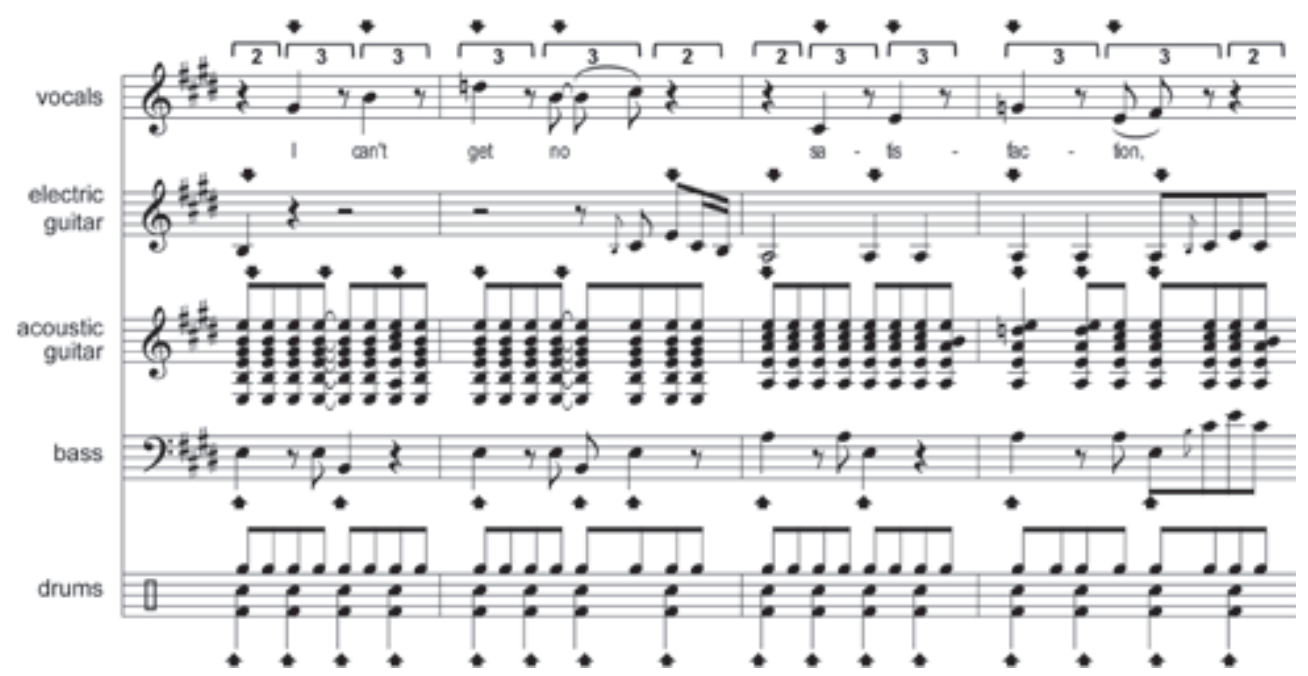

Figure 13.4 Rolling Stones, “(I Can't Get No) Satisfaction”, first phrase of verse 1

answering the vocal melody with brief fills at the end of every second bar, but also joining the bass in emphasising beats 1 and 3 at the end of the phrase. The rhythm guitar, which is low in the mix, initially suggests a 332 tresillo grouping in the first two bars that aligns with the vocals in the second bar, but then shifts to mostly straight quavers. Although the double tresillo in the melody is a generally common rhythm in popular music, in this instance it works particularly well to depict the frustration of the poetic persona expressed in the lyrics (who "can't get no satisfaction"). Other rhythmically dissonant melodies that resolve at the end of the phrase are the chorus of Kansas' "Carry On Wayward Son", the verse of Black Sabbath's "Paranoid", and the refrain of Led Zeppelin's "Rock and Roll". ${ }^{29}$ The refrain of Cream's "Sunshine of Your Love" is similar in that the quaver-displaced melody resolves on the downbeat of the seventh bar, but the explicit beat layer is an anomalous reverse backbeat, with snare on beats 1 and 3 and kick drum on beats 2 and 4 .

Another common rhythmic function of the melodic layer is to end-weight phrases or sections through increased density of note attacks. This rhythmic trajectory likely derives from the twelve-bar blues, in which the $\mathrm{B}$ phrases of the $\mathrm{AAB}$ pattern customarily feature greater rhythmic and harmonic density that create a sense of culmination. Figure 13.5 shows an example of increased rhythmic activity within a phrase, from the chorus of Aerosmith's "Dream On" (1973). ${ }^{30}$ The slower and unchanging rhythms in the rest of the coordinated texture form a fixed background that highlights the rhythmic intensification in the melody. The second phrase is parallel, with the addition of a long-held note at the end that contributes to a sense of arrival. Other instances of phrases that increase in rhythmic density are the verses of AC/DC's "Back in Black" and the Rolling Stones' "Angie", and the opening of Billy Joel's "Italian Restaurant."

At the section level, increases in rhythmic density most typically occur in the verse or prechorus; as discussed below, chorus rhythms tend to be more regular. One example is the verse of Yes's "Roundabout" (1971). The melody of the first verse is shown in Figure 13.6; other verses follow the same rhythmic and metric pattern. Although the hypermetre and grouping structure are not completely regular-note the two $6 / 4$ bars in the second halfthe increases in rhythmic density are clear. Line 2 (bars 3-4) is denser than line 1, and line 4 


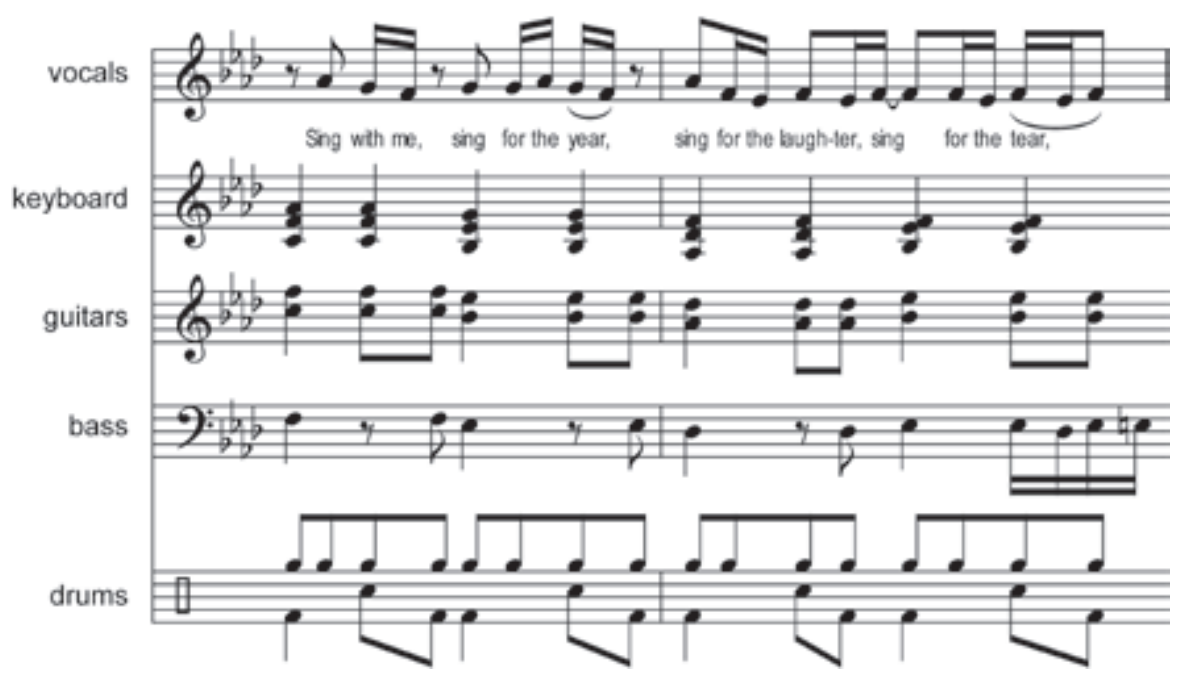

Figure 13.5 Aerosmith, "Dream On”, first phrase of chorus 2
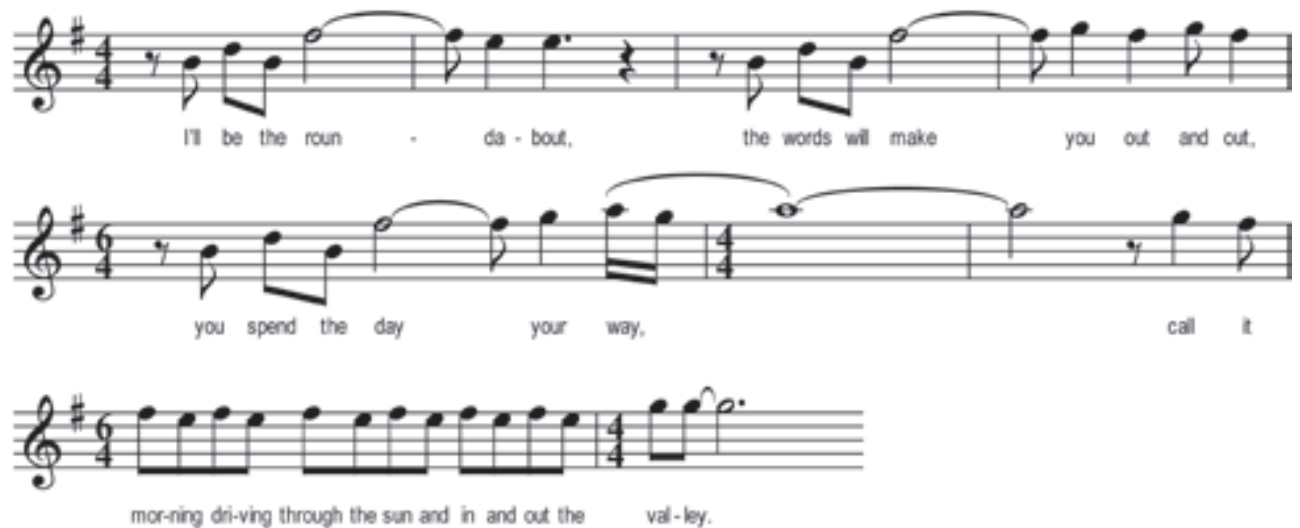

Figure 13.6 Yes, "Roundabout", melody of verse 1

is denser still than lines 1,2 and 3, creating a peak of rhythmic intensity in the last line of the verse. As in the Aerosmith example, the final syllable is a long-held note that signals the end of the section. Comparable examples are the verses of The Beatles" "Dear Prudence", David Bowie's "Diamond Dogs", and The Police's "Every Breath You Take."

As the examples above have demonstrated, some common functions of the variable rhythmic layer - in these examples, the melodic layer - are to complement the fixed rhythmic layer, to contribute to a sense of resolution at the end of a phrase or section by progressing from rhythmic dissonance to rhythmic consonance, and to create momentum and point toward the end of a phrase or section with increased density of note attacks. In the next section of this chapter, I survey the normative rhythmic characteristics of standard rock song sections (introductions, verses, choruses, prechoruses, and bridges), ${ }^{31}$ and explore the functions of rhythmic layers within and between sections through sample analyses.

Introduction sections in rock songs are often formally and/or texturally incomplete. In some cases, songs begin with an incomplete version of the verse, or more often the 
chorus-which is common enough in the Beatles' music for Covach to call it "Beatles verse-chorus form". ${ }^{32}$ Most typically, however, rock introductions begin with a thin instrumental texture that is gradually thickened over the course of the section: a buildup introduction. The gradual addition of layers intensifies not only the texture but also the dynamics, registral space, timbral variety, and rhythmic complexity. The first entry in a buildup introduction is typically not the drums, but a melodic or harmonic layer played by guitar or keyboard, which frequently exploits the lack of an explicit rhythm layer by suggesting a different grouping or downbeat that contradicts the underlying metre or renders it ambiguous, which Justin London has called a "metric fake-out". ${ }^{33}$ Thus introduction sections are often rhythmically or metrically unstable as well as formally or texturally incomplete. The overall effect of introductions is anticipatory, creating the expectation of a more complete section that includes the vocal entry to follow.

Bon Jovi's "Runaway" (1984) features a rhythmically asymmetric and thus potentially metrically ambiguous introduction (see Figure 13.7). The song begins with the harmonic layer alone; the even quavers in the solo synthesiser are grouped into a 333322 double tresillo rhythm by changes in the pitch content of the chords. This pattern repeats through the verse of the song, but the backbeat is withheld until halfway through the verse. Because the pattern repeats, and because clave-based patterns are so common in rock, experienced listeners are likely to perceive it as provisionally in 4/4, but the meter is not confirmed until halfway through the verse. After the first four bars of the introduction, the drums and bass punctuate the texture with an upbeat-downbeat figure every two bars, and in the second line of the verse they accelerate, punctuating every half-bar. Such a rhythmic intensification creates a strong sense of anticipation and increased momentum. At the third line of the verse, a regular backbeat is instantiated, along with guitars and backing vocals. The clarified metre and denser texture contribute to an emphatic sense of arrival at this point. Thus, the first half of the verse retains some introductory function.

Harald Krebs refers to patterns of triple groupings in a duple or quadruple contextand more generally, any rhythmic grouping that diverges from the metre-as "grouping dissonances", and they are quite common in introduction sections. "Displacement dissonances", by contrast, have groupings that would be consonant with the metre but are out of alignment, shifted forward or back in time. ${ }^{35}$ Introductions featuring displacement dissonances are much rarer, especially in songs that begin without the drums, because unlike grouping dissonances, displacement dissonances do not periodically realign with the underlying metre; they thus present a stronger challenge to it. One example is "Hell's Bells" (1980) by AC/DC, which begins with a bell that text-paints the title, followed by a melodic layer in the guitar (see Figure 13.8). After the initial attack, the melody is displaced backward by one quaver for the rest of the long introduction. The four bell strokes that begin the song are two bars apart, implicitly on the hyperdownbeats. However, once the guitar enters, the bell shifts to beat 2 . Thus this passage features two levels of displacement, one in each

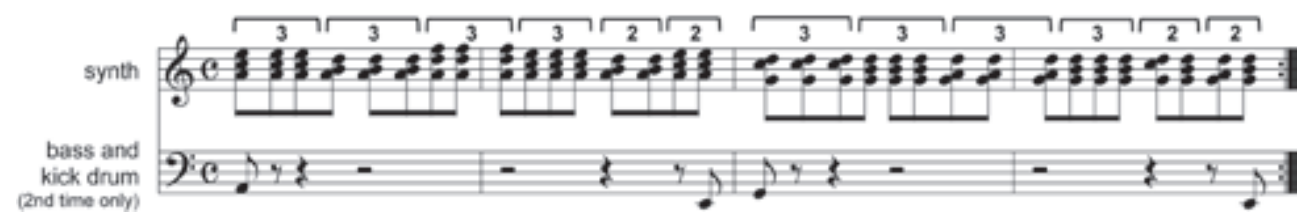

Figure 13.7 Bon Jovi, “Runaway", introduction 


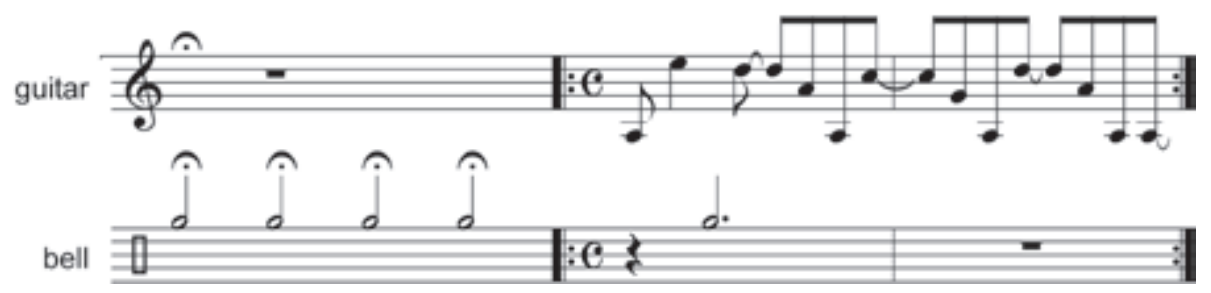

Figure 13.8 AC/DC, "Hell's Bells", introduction

direction: the guitar is displaced backward in time by a quaver, and the bell is displaced forward by a crotchet. Nonetheless, the contour and rhythm of the melody suggest a 4/4 metre, particularly in the absence of any other conflicting cues, so the destabilisation is a mild one.

The contrasting relationship between verse and chorus sections has been described by David Temperley and named "loose-verse/tight-chorus" or LVTC form. ${ }^{36}$ In this paradigm, choruses are more regular than verses in terms of lyrics, texture, phrase structure, harmonic rhythm, and melodic rhythm; in addition, they are also usually louder and have a thicker texture, thus functioning as both contrast and culmination within the overall form. Verses are more likely to have a faster melodic rhythm and sometimes a slower harmonic rhythm than choruses, which typically have a slower melodic rhythm than the verse, emphasising the repeated chorus lyric, and sometimes a faster harmonic rhythm, which adds intensity and interest to this focal section. Verses and choruses can be connected by a tension-building prechorus section, which functions much like a transition section, frequently featuring tonal and/or harmonic instability, a fragmented phrase structure, a change in rhythmic density, and often registral expansion. ${ }^{37}$ Bridge sections have similar characteristics, but different positions and functions within the form: bridges are contrasting developmental sections, usually located outside of the verse-chorus unit.

Jimi Hendrix's "Spanish Castle Magic" (1967) demonstrates some of the textural and rhythmic contrasts between verse and chorus. The opening of each section is shown in Figure 13.9. In the verse (Figure 13.9a), the drums, bass and guitar play a tattoo figure that takes up the first half of every bar, and is repeated in the second half of bar 2, creating a large-scale hypermetric march pattern with a subdivision in the second bar. Between the tattoos, the bass drum plays quavers and Hendrix sings mostly in semiquavers in the second half of each bar, in a loose call-and-response format. The change of both rhythmic pattern and texture every half bar has a fragmented effect, enhanced by the chromatically descending harmonies. The chorus (Figure 13.9b) is texturally and rhythmically more consistent than the verse: the slower melodic rhythm in the vocals is loosely mirrored in the guitar, bass, and piano, and the drums shift to an ornamented backbeat pattern.

The looseness of the verse and tightness of the chorus are not always created by melodic and harmonic rhythm. In Heart's power ballad "Alone" (1987), the melodic and harmonic rhythm are fairly consistent across the verse, prechorus, and chorus, and the accompaniment rhythm in the verse and prechorus is, unusually, more regular than the rhythm in the chorus, as shown in the chart of Table 13.1. This is because there are no drums until the chorus, so the keyboards assume the timekeeping role in the verse and prechorus, joined by the bass, which enters halfway through the verse. The entrance of the drums in the chorus allows the accompaniment parts to shift to a syncopated pattern grouped as $3+5$ quavers, a pattern closely related to the tresillo that can be interpreted as combining its last two attacks 


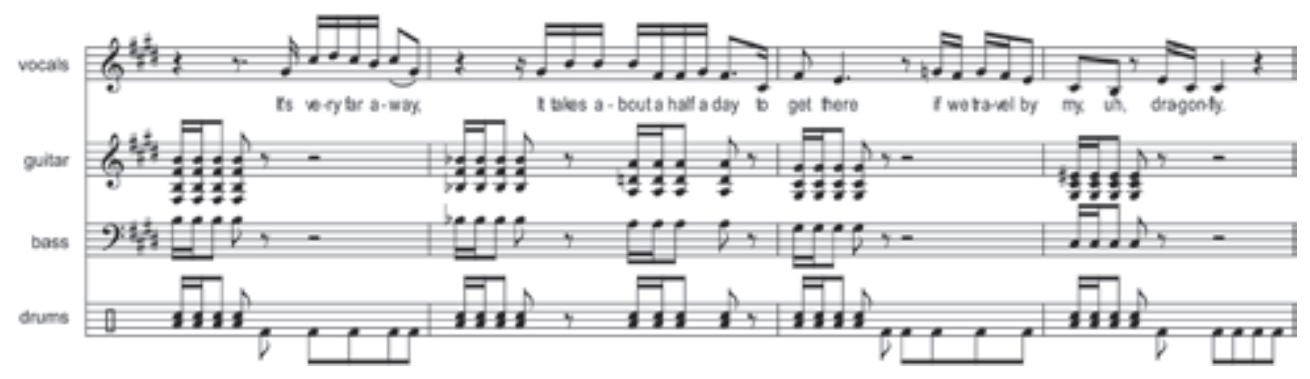

Figure 13.9a Jimi Hendrix, "Spanish Castle Magic", beginning of verse

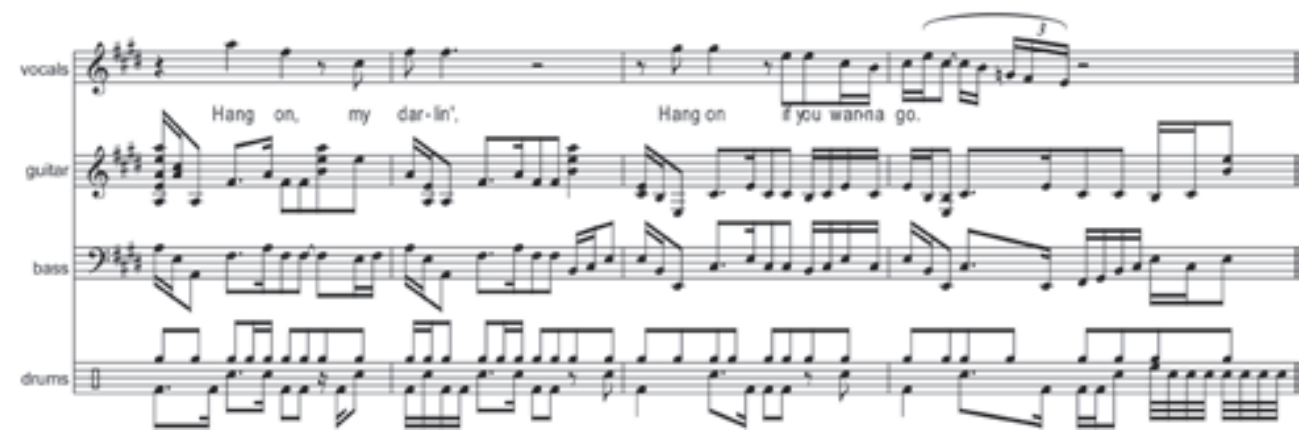

Figure 13.9b Jimi Hendrix, "Spanish Castle Magic”, beginning of chorus

Table 13.1 Heart, “Alone”, rhythm layers in verse, prechorus, and chorus

\begin{tabular}{|c|c|c|c|}
\hline & Verse & Prechorus & Chorus \\
\hline Key & B) minor & Db major & G) major \\
\hline Instrumentation & vocals, keyboard + bass & + synth strings & + drums \\
\hline Vocal Rhythm & $\begin{array}{l}\text { quavers } \\
\text { (some syncopation) }\end{array}$ & $\begin{array}{l}\text { quavers, semiquavers } \\
\text { (some syncopation) }\end{array}$ & $\begin{array}{l}\text { quavers, crotchets } \\
\text { (mostly even) }\end{array}$ \\
\hline $\begin{array}{l}\text { Keyboard RH } \\
\text { Rhythm }\end{array}$ & even quavers & even quavers & $3+5$ grouping \\
\hline Bass Rhythm & minims & minims & $\begin{array}{l}\text { alternating quavers and } \\
3+5\end{array}$ \\
\hline Drum Rhythm & - & - & backbeat \\
\hline
\end{tabular}

(332 becomes 35). The chorus also features dramatic expansions of texture, dynamics, and register that help to establish its role as the focal section of the form.

Metre, in addition to texture and rhythm, helps to define the formal sections in Cream's "White Room" (1968). The form and rhythmic characteristics of each section are shown in Table 13.2. The introduction, which recurs at the midpoint and end of the song, is in $5 / 4$, an asymmetrical metre that contrasts with the regular $4 / 4$ of the verse and chorus (the introduction is also tonally ambiguous and does not clearly establish a key). The metre is defined only in the timpani, with the drum kit marking the downbeats; the other parts are 
Table 13.2 Cream, "White Room”, formal plan and section characteristics

\begin{tabular}{|c|c|c|c|}
\hline \multicolumn{4}{|c|}{ Intro-Verse-Chorus-Verse-Chorus-Intro-Verse-Chorus-Intro-Solo } \\
\hline & Intro & Verse & Chorus \\
\hline Metre & $5 / 4$ & $4 / 4$ & $4 / 4$ \\
\hline Vocal Rhythm & long notes ( 1 per bar) & $\begin{array}{l}\text { syncopated, some triplets; } \\
\text { 1-bar motives directed } \\
\text { toward downbeats }\end{array}$ & $\begin{array}{l}\text { mostly triplets; } 2 \text {-bar } \\
\text { motives directed away } \\
\text { from downbeats }\end{array}$ \\
\hline $\begin{array}{l}\text { Guitar } \\
\text { Rhythm }\end{array}$ & long notes ( 1 per bar) & $\begin{array}{l}\text { crotchets and quavers, } \\
\text { mostly on the beat }\end{array}$ & long notes ( 1 per bar) \\
\hline Bass Rhythm & long notes ( 1 per bar) & $\begin{array}{l}\text { crotchets and quavers, } \\
\text { mostly on the beat }\end{array}$ & $\begin{array}{l}\text { dotted crotchet - } \\
\text { quaver - crotchet }\end{array}$ \\
\hline $\begin{array}{l}\text { Percussion } \\
\text { Rhythm }\end{array}$ & $\begin{array}{l}\text { 5/4 march rhythm } \\
\text { w/triplets }\end{array}$ & $\begin{array}{l}\text { backbeat with } \\
\text { quaver hi-hat }\end{array}$ & $\begin{array}{l}\text { backbeat with crotchet } \\
\text { hi-hat }\end{array}$ \\
\hline
\end{tabular}

rhythmically static, holding their notes for the duration of each bar. The verse melody is a series of one-bar motives that descend sequentially through a tenth, emphatically arriving on the downbeats, although most of the other notes in the melody are rhythmically dissonant. The guitar and bass play differentiated rhythms that generally mark the beats, creating a loose-knit texture in the verse. The chorus is comparatively tight-knit, with the guitars returning to the static rhythm of the introduction, and the bass playing a regular dotted rhythm. The vocals continue to emphasise the downbeats, but now as a point of departure rather than a point of arrival. The falsetto register and legato rhythm of the melody in the chorus contribute some bridge-like qualities to this section, but the alternating repetition scheme, longer phrase lengths and harmonic closure on an Aeolian cadence are typical chorus characteristics.

Rush's "Freewill" (1980) has a more complex song structure that includes a prechorus and a solo bridge. The formal plan and section characteristics are given in Table 13.3. The song begins with two descending scales in the guitar-perhaps the rock-music equivalent of a premier coup d'archet? The bass and drums play syncopated accents underneath the opening scales, creating a mild rhythmic tension. After the initial two bars, the metre alternates between bars of 6 and bars of 7, forming a larger non-isochronous cycle of 13 beats. The additive structure of the changing metre is clarified because the beginning of each bar is melodically marked by an ascending-fifth motive, and rhythmically marked by an anticipation of beat 2 in the melody, which suggests two triple-quaver groupings at the beginning of each bar. The end of each bar is signalled in the drum part by a shift from the backbeat pattern to extra hits or fills that adjust to the varying bar lengths. This pattern continues in the verse.

Metrically, the prechorus is more stable than the verse, establishing a regular 4/4 metre, but there are slight rhythmic displacements in the vocals and different small-scale displacements in the guitar and bass, so the texture is the most stratified thus far. The drums shift to a half-time pattern, allowing for an intensification in this layer when a standard backbeat arrives with the chorus.

The chorus section is comparatively tight-knit; the metre is a regular $4 / 4$, and the texture is the most coordinated in the song. The first three phrases end with truncated bars of $3 / 4$, which create momentum. In phrases 1 and 3 these are emphasised by snare hits on beats 2 


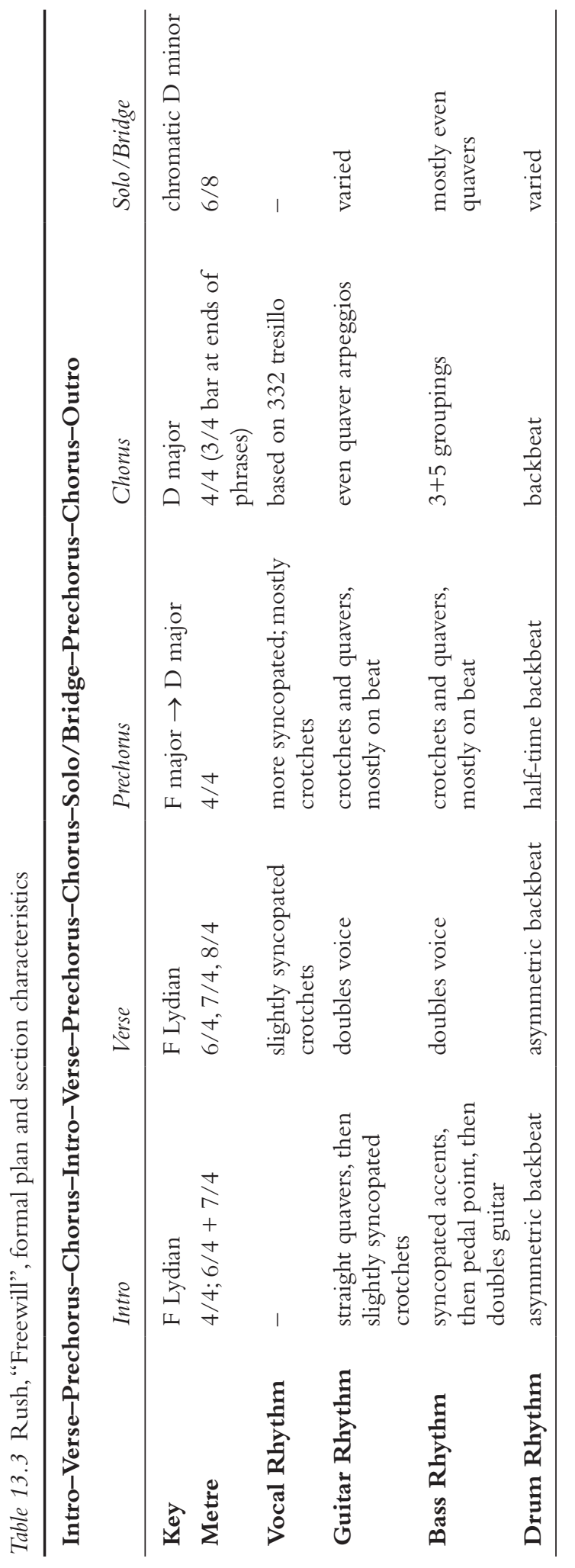




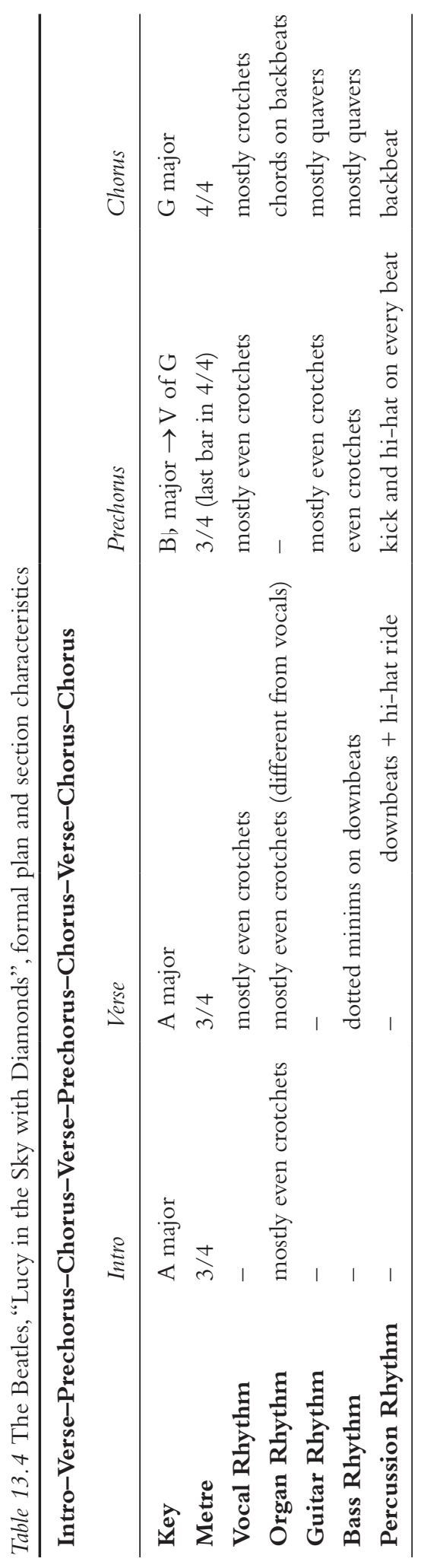


and 3, as if affirming the lyrics (this is a canonical air-drumming moment at live performances). The final bar is not truncated, but remains in 4/4 to enhance the contrast with the changing metre of the next verse.

The bridge section creates contrast in numerous domains: texture, tonality, phrase structure, intervallic dissonance, timbral dissonance, increased rhythmic density, and registral extremes. The bridge also has a contrasting metre, 6/8, which is more regular than the changing metre of verse-but solo sections are normally in a regular metre to simplify the framework for improvisation, and the $6 / 8$ of the bridge is less normative than the $4 / 4$ of the chorus that precedes it and the prechorus that follows it.

An extraordinary instance of a large-scale trajectory of increasing rhythmic intensification is The Beatles' "Lucy in the Sky with Diamonds" (1967). Table 13.4 shows the formal plan and section characteristics. Like "Free Will", this song features sharp contrasts between verse and chorus in the domains of tonality and metre, necessitating a transitional prechorus. The variegated sections of this song are connected, however, by the clear trajectory of acceleration in the accompaniment rhythms, which are absent in the introduction, and which mark each downbeat in the verse, each beat in the prechorus, and each beat subdivision in the chorus. Combined with the textural expansion and regularisation of the metre, the large-scale acceleration in the rhythm layer contributes to the sense of chorus as culmination. The acceleration itself is compressed at the end of the song, when the third verse moves directly to a repeated chorus, skipping the transitional prechorus.

In conclusion, I have demonstrated a variety of rhythmic functions within different textural layers, and within and between formal sections of some pop-rock songs. Common functions of rhythm in the melodic layer are: to complement the accents in the explicit beat layer, to create momentum within a phrase or section through increased rhythmic density, and to contribute to a sense of arrival at the end of a phrase or section by resolving from dissonance to consonance. Common functions of rhythm within formal sections are to destabilise the metre through rhythmic dissonance in introduction sections, to contribute to the loose-knit organization of verse sections through greater rhythmic stratification and complexity, and to contribute to the tight-knit organization of choruses through regular rhythms and more homorhythmic textures. Between song sections, rhythmic and metric shifts mark the formal boundaries of phrases, sections, and section groupings, and help to articulate larger trajectories of increasing and decreasing intensity throughout the song. Further research on this topic will include a larger corpus of examples, investigate changes in rhythmic patterns over time, and examine and compare the interactions of rhythm and form in other related genres. As noted at the opening of this chapter, rhythm is one of the most salient parameters in rock music, and it is also one of the most complex. Much work remains to be done on this topic, but I hope here to have made a beginning.

\section{Notes}

1 See, for example: Timothy Hughes, "Groove and Flow: Six Analytical Essays on the Music of Stevie Wonder" (PhD diss., University of Washington, 2003); Lawrence Zbikowski, "Modelling the Groove: Conceptual Structure and Popular Music," Journal of the Royal Musical Association CXXIV, no. 2 (2004): 272-97; Mark Butler, Unlocking the Groove: Rhythm, Meter, and Musical Design in Electronic Dance Music (Bloomington, IN: Indiana University Press, 2006); Anne Danielsen, Presence and Pleasure: The Funk Grooves of James Brown and Parliament 
(Middleton, CT: Wesleyan University Press, 2006), and "The Sound of Crossover: MicroRhythm and Sonic Pleasure in Michael Jackson's ‘Don't Stop 'Til You Get Enough',' Popular Music and Society XXXV, no. 2 (2012): 151-68; Robert Fink, "Goal-Directed Soul? Analyzing Rhythmic Teleology in African American Popular Music," Journal of the American Musicological Society LIV, no. 1 (2011): 179-238.

2 Olly Wilson, "The Significance of the Relationship between Afro-American Music and West African Music," The Black Perspective in Music II (1974): 3-23; Vijay Iyer, "Macrostructures of Feel, Microstructures of Sound: Embodied Cognition in West African and African-American Musics" (PhD diss., University of California at Berkeley, 1998).

3 Jonathan Pieslak, "Re-casting Metal: Rhythm and Meter in the Music of Meshuggah," Music Theory Spectrum XXIX, no. 2 (2007): 219-45; John Brackett, "Examining Rhythmic and Metric Practices in Led Zeppelin's Musical Style," Popular Music XXVII, no. 1 (2008): 53-76; John Covach, "Textural Stratification in Rock Music," University of Rochester Institute for Popular Music lecture, 2014: www.youtube.com/watch?v=of3UxtvvmAQ; "Musical Worlding in a 'Roundabout' Way," Unpublished paper presented at the Yale Department of Music, New Haven, CT, 9 March 1998; and "Some Remarks on Textural Stratification in 20th-Century Music," Unpublished paper presented at the Eastman School of Music, Rochester, NY, 2001: https://rochester.academia.edu/JohnCovach. See also Henry Martin, Cynthia Folio, Steve Larson, Lori Burns, John Covach, and Walker Everett, "Report on the 2008 Mannes Institute for Advanced Studies in Music Theory: Jazz Meets Pop," Music Theory Online XIV, no. 3 (2008): 30-34.

4 Robin Attas, "Meter as Process in Groove-Based Popular Musics" (PhD diss., University of British Columbia, 2011).

5 See, for instance: Henry Cowell, New Musical Resources (New York: Alfred A. Knopf, 1930); Edward Cone, "Stravinsky: The Progress of a Method," Perspectives of New Music I, no. 1 (1982): 18-26; Elliott Carter, "The Rhythmic Basis of American Music," in The Writings of Elliott Carter, edited by Else Stone and Kurt Stone (Bloomington, IN: Indiana University Press, 1977), 160-66; Katherine Covington, "A Study of Textural Stratification in TwentiethCentury Compositions" (PhD diss., Indiana University, 1982); Jonathan Bernard, "The Evolution of Elliott Carter's Rhythmic Practice," Perspectives of New Music XXVI, no. 2 (1988): 164-203; John Roeder, "Interacting Pulse Streams in Schoenberg's Atonal Polyphony," Music Theory Spectrum XVI, no. 2 (1994): 231-49, and "Pulse Streams and Problems of Grouping and Metrical Dissonance in Bartók's 'With Drums and Pipes'," Music Theory Online VII, no.1 (2001); Gretchen Horlacher, "The Rhythms of Reiteration: Formal Development in Stravinsky's Ostinati," Music Theory Spectrum XIV, no. 2 (1992): 171-87; Margaret Thomas, "Conlon Nancarrow's 'Temporal Dissonance': Rhythmic and Textural Stratification in the Studies for Player Piano" (PhD diss., Yale University, 1996).

6 Maury Yeston, The Stratification of Musical Rhythm (New Haven: Yale University Press, 1976).

7 See: David Temperley, "Syncopation in Rock: A Perceptual Perspective," Popular Music XVIII (1999): 19-40; Don Traut, “'Simply Irresistible': Recurring Accent Patterns as Hooks in Mainstream 1980s Music," Popular Music XXIV, no. 1 (2005): 57-77; David Huron and Ann Ommen, "An Empirical Study of Syncopation in American Popular Music, 1890-1939," Music Theory Spectrum XXVIII, no. 2 (2006): 211-32; Brad Osborn, "Kid Algebra: Radiohead's Euclidean and Maximally Even Rhythms," Perspectives of New Music LII, no. 1 (2014): 81-105; Richard Cohn, "A Platonic Model of Funky Rhythms," Music Theory Online XXII, no. 2 (2016); Scott Murphy, "Cohn's Platonic Model and the Regular Irregularities of Recent Popular Multimedia,” Music Theory Online XII, no. 3 (2016).

8 Albert Bregman, Auditory Scene Analysis: The Perceptual Organization of Sound (Cambridge, MA: MIT Press, 1990).

9 The term first appears in: Allan Moore, “The So-Called 'Flattened Seventh' in Rock," Popular Music XIV, no. 2 (1995): 185-201,189; and the concept has been further explored by Temperley, "Syncopation in Rock: A Perceptual Perspective". See also Drew Nobile, "Counterpoint in Rock Music: Unpacking the 'Melodic-Harmonic Divorce'," Music Theory Spectrum XXXVII, 
no. 2 (2016): 189-203. See also de Clercq, Trevor, "The Harmonic-Bass Divorce in Rock: A Method for Conceptualizing the Organization of Chord Extensions," unpublished paper presented at Music Theory Midwest meeting, University of Arkansas, AR, 6 May 2016.

10 Mark Spicer describes the initial expansion of texture common in pop-rock music as an accumulative beginning. See "(Ac)cumulative Form in Pop-Rock Music," twentieth-century music I, no. 1 (2004): 32-33. Mark Butler uses the more colloquial term "buildup" for sections of electronic dance music that may or may not be introductory (Unlocking the Groove: Rhythm, Meter, and Musical Design in Electronic Dance Music). Robin Attas ("Form as Process: The Buildup Introduction in Popular Music," Music Theory Spectrum XXXVII, no. 2 (2015): 275-96) adopts this term in her exploration of buildup introductions in pop and rock music.

11 Charles Keil, “The Theory of Participatory Discrepancies: A Progress Report,” Ethnomusicology XXXIX, no. 1 (1995): 1-19. Iyer, Vijay, "Macrostructures of Feel, Microstructures of Sound: Embodied Cognition in West African and African-American Musics" (PhD diss., University of California at Berkeley), and "Embodied Mind, Situated Cognition, and Expressive Microtiming in African-American Music," Music Perception IX, no. 3 (2002): 387-414; Matthew Butterfield, "The Power of Anacrusis: Engendered Feeling in Groove-Based Musics," Music Theory Online XII, no. 4 (2006); Anne Danielsen, "Introduction: Rhythm in the Age of Digital Reproduction," in Musical Rhythm in the Age of Digital Reproduction, edited by Anne Danielsen (Burlington, VT: Ashgate, 2010), 1-16.

12 See William Caplin, Classical Form: A Theory of Formal Functions for the Instrumental Music of Haydn, Mozart, and Beethoven (Oxford University Press, 1998), and Analyzing Classical Form: An Approach for the Classroom (Oxford University Press, 2013).

13 Covach, "Textural Stratification in Rock Music."

14 Olly Wilson, "The Significance of the Relationship between Afro-American Music and West African Music," The Black Perspective in Music II (1974): 3-23; Lee Cronbach, "Structural Polytonality in Contemporary Afro-American Music," Black Music Research Journal II (198182): 15-33; Kyle Adams, "Aspects of the Music/Text Relationship in Rap," Music Theory Online XIV, no. 2 (2008).

15 Jeff Pressing, "Black Atlantic Rhythm: Its Computational and Transcultural Foundations," Music Perception XIX, no. 3 (2002): 285-310.

16 Trevor de Clercq, "The Harmonic-Bass Divorce in Rock: A Method for Conceptualizing the Organization of Chord Extensions."

17 Allan F. Moore, Song Means: Analysing and Interpreting Recorded Popular Song (Surrey: Ashgate Publishing, 2012), 19-21.

18 Jeff Pressing ("Black Atlantic Rhythm: Its Computational and Transcultural Foundations") asserts that the rhythmic dissonance and complex layering typical in music of the Black Atlantic diaspora serves to create perceptual multiplicity, which in turn fosters dance or other kinesthetic engagement and social interaction.

19 For discussions of the mid-century shift from triple to duple subdivision in American popular music, see: Alexander Stewart, “Funky Drummer': New Orleans, James Brown and the Rhythmic Transformation of American Popular Music," Popular Music XIX, no. 3 (2000): 293-318; Fernando Benadon and Ted Gioia. "How Hooker Found his Boogie: A Rhythmic Analysis of a Classic Groove," Popular Music XXVIII, no. 1 (2009): 19-32.

20 Nicole Biamonte, "Formal Functions of Metric Dissonance in Rock Music," Music Theory Online XX, no. 2 (2014): [6.2].

21 Vijay Iyer, "Embodied Mind, Situated Cognition, and Expressive Microtiming in AfricanAmerican Music," Music Perception IX, no. 3 (2002): 387-414, 406.

22 Iyer, "Embodied Mind, Situated Cognition, and Expressive Microtiming in African-American Music," 406; Butterfield, "The Power of Anacrusis: Engendered Feeling in Groove-Based Musics." In the Rolling Stones' "Time Is on My Side", drummer Charlie Watts plays a late snare backbeat; in Michael Jackson's "Billie Jean", Ndugu Chancler plays the snare backbeat very slightly early. 
23 Robert Fink refers to such stable patterns as "tonic rhythms", although his discussion focuses on the four-on-the-floor pattern, described briefly below ("Goal-Directed Soul? Analyzing Rhythmic Teleology in African American Popular Music," 199).

24 This is, of course, a broad generalization; numerous rock drummers, including Keith Moon of The Who and Mitch Mitchell of The Jimi Hendrix Experience, are well known for their avoidance of repeated patterns in favour of rhythmic (and timbral) variety.

25 For a nuanced discussion of bar lengths in pop-rock, including examples of half-time and double-time backbeats, see Trevor de Clercq, "Measuring a Measure: Absolute Time as a Factor for Determining Bar Lengths and Meter in Pop/Rock Music," Music Theory Online XX, no. 3 (2016).

26 Mark Butler, Unlocking the Groove: Rhythm, Meter, and Musical Design in Electronic Dance Music (Bloomington, IN: Indiana University Press, 2006); Charles Kronengold, "Exchange Theories in Disco, New Wave, and Album-Oriented Rock," Criticism L, no. 1 (2008): 43-82; Robin Attas, "Meter as Process in Groove-Based Popular Musics" (PhD diss., University of British Columbia, 2011).

27 Discussed in David Temperley, "Syncopation in Rock: A Perceptual Perspective."

28 "Tresillo" is the term for the 332 grouping of the first bar of the forward clave rhythm (33242); "double tresillo" is my term for the extended two-bar version of this rhythm, 333322. The next most common version of this pattern is the rotation that begins with a duple grouping, 233332, as in Figure 13.4 and the melody of Gershwin's "I Got Rhythm" (thanks to Dmitri Tymoczko for pointing out this correspondence). See Traut, “'Simply Irresistible': Recurring Accent Patterns as Hooks in Mainstream 1980s Music" and Biamonte, "Formal Functions of Metric Dissonance in Rock Music". For more examples of clave-based patterns see Cohn, "A Platonic Model of Funky Rhythms" and Murphy, "Cohn's Platonic Model and the Regular Irregularities of Recent Popular Multimedia."

29 As discussed in Biamonte, "Formal Functions of Metric Dissonance in Rock Music" (Exx. 3a, $3 \mathrm{~b}$, and $11 \mathrm{~b}$ respectively).

30 The first occurrence of this section has several chorus-like characteristics: compared to the verse, it has a thicker texture, more static tonic-focused harmony, more regular rhythm, louder dynamic, and more emphatic explicit beat layer. However, the lyrics do not contain the title text and are not repeated. Later iterations of this section more clearly function as a chorus. For a discussion of conversions and blends of different formal sections in pop-rock music see Trevor de Clercq, "Sections and Successions in Successful Songs: A Prototype Approach to Form in Rock Music" (Ph.D. diss., Eastman School of Music, 2012).

31 For a detailed exploration of the formal roles of pop-rock song sections see de Clercq, "Sections and Successions in Successful Songs: A Prototype Approach to Form in Rock Music."

32 John Covach, "From 'Craft' to 'Art': Formal Structure in the Music of The Beatles," in Reading The Beatles: Cultural Studies, Literary Criticism, and the Fab Four, eds. Kenneth Womack and Todd F. Davis (Albany, NY: State University of New York Press, 2006), 43.

33 Justin London, "Metric Fake Outs" (2006). Excel spreadsheet posted at http://people.carleton. edu/ jlondon.

34 Harald Krebs, Fantasy Pieces: Metrical Dissonance in the Music of Robert Schumann (Oxford: Oxford University Press, 1999), 31-33; Ch. 2ff.

35 Krebs, Fantasy Pieces: Metrical Dissonance in the Music of Robert Schumann, 33-38.

36 Temperley, “The Melodic-Harmonic 'Divorce' in Rock.” Popular Music XXVI, no. 2 (2007): 335-39.

37 For more on prechorus sections, see Jay Summach, "The Structure, Function, and Genesis of the Prechorus,” Music Theory Online XVII, no. 3 (2011). 